\title{
Decision Making in the Tea Leaves Diseases Detection Using Mamdani Fuzzy Inference Method
}

\author{
Arif Ridho Lubis ${ }^{1}$, Santi Prayudani ${ }^{2}$, Muharman Lubis ${ }^{3}$, Al-Khowarizmi ${ }^{4}$ \\ ${ }^{1,2,4}$ Department of Computer Engineering and Informatics, Politeknik Negeri Medan, \\ Jalan Almamater No. 1, 20155, Medan, North Sumatera, Indonesia \\ ${ }^{3}$ School of Industrial Engineering, Telkom University Jalan Telekomunikasi, No. 1, Bandung, 40257, Indonesia
}

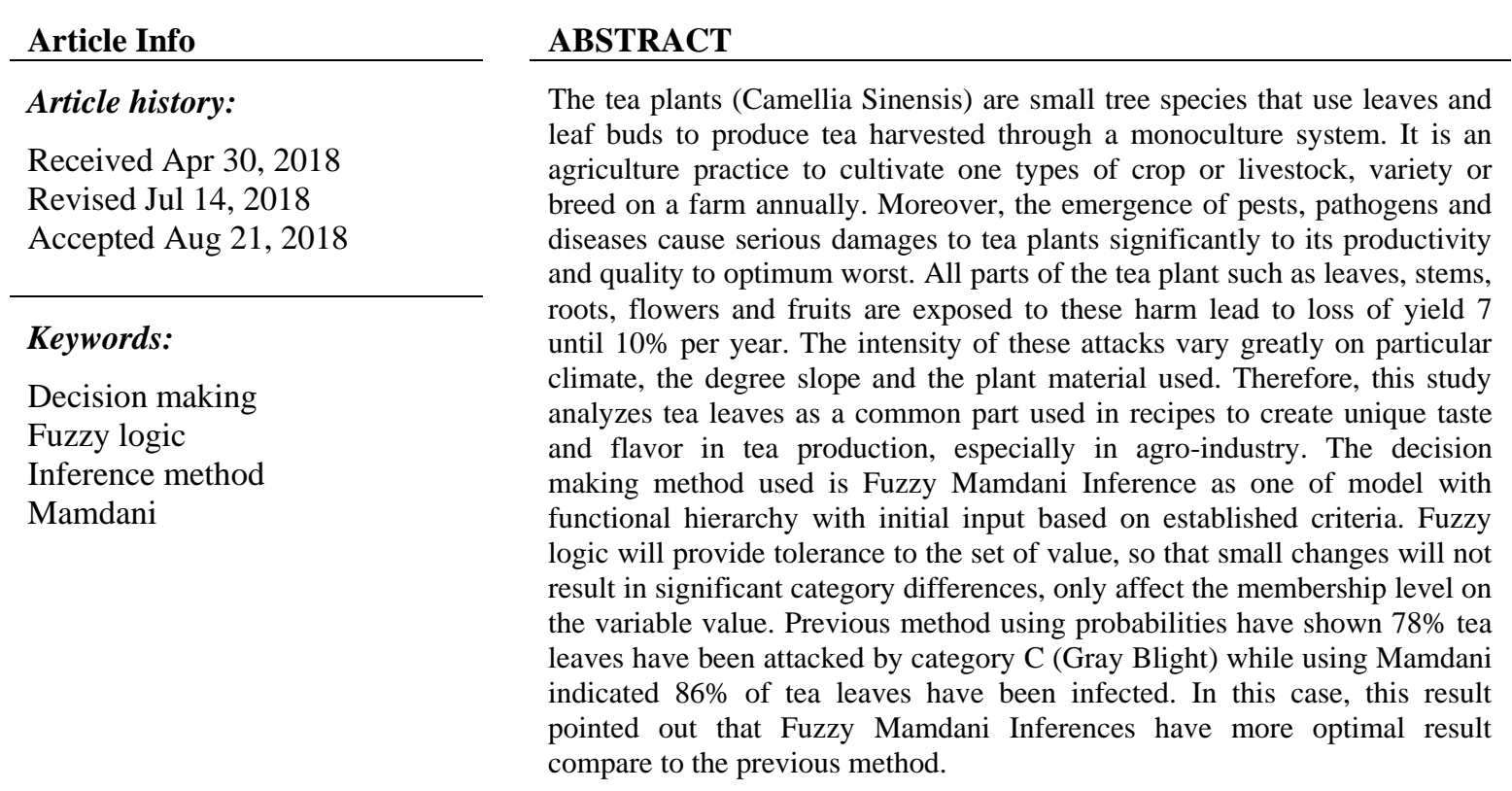

Copyright $@ 2018$ Institute of Advanced Engineering and Science. All rights reserved.

\section{Corresponding Author:}

Arif Ridho Lubis,

Department of Computer Engineering and Informatics,

Politeknik Negeri Medan,

Jalan Almamater No. 1, 20155, Medan, North Sumatera, Indonesia.

Email: arifridho@polmed.ac.id

\section{INTRODUCTION}

Today the development of IT has been so rapid, not limited to the development of hardware and software, but also the computing method such as the decision-making system. It is a branch of science that its concept lies and used frequently between IS and AI field. The ability to quickly decide on particular them based on context, right on target and accountable is the critical factor to be success in the global competition. Having a lot of information is not sufficient, if not able to do decision-making properly such as alternative identification, weight the evidence and reviewing scheme. Prior to choose among alternatives, several criterions should be established first, in which it should be able to answer important question about how well an alternative can solve a problem at hand. Using step-by-step decision-making system can help to make more informed assessment by organizing relevant information in proper structure and systematically. In the end, the organization often struggle from the after effect of an incident which may create damage and harm to the reputation, finances and worker performances [13]. 
Tea is a beverage made by steeping leaves in boiling water, which low-grown teas are produce from 0-600m, mid-grown from 600-1,200m while the high-grown teas are cultivated between 1,200-2,000m [1]. Meanwhile, the tea plant needs a hot, moist climate with its specific requirements are ranging temperatures from $10-30 \mathrm{oC}$, minimum annual precipitation of $1250 \mathrm{~mm}$, preferably acidic soils and ideally $0.5-10$ degree slopes [2]. Most of the tea world production based on FAO 2013's report is produced (thousand tons) in Far East (3,965.6/78.31\%), which majority is in China (Mailand), India, Srilanka, Vietnam and Indonesia, then in Africa $(649.5 / 12.82 \%)$ that is mostly in Kenya and Uganda, followed by Near East $(253.5 / 5 \%)$, Latin Caribbean (95/2\%), Japan (84.7/1.6\%) and Oceania (6.5/0.1\%) [2]. Furthermore, many of the pests, pathogens and diseases that affect the tea plan, in which it was recorded that 1034 species of arthropod (mostly from butterflies and moth), 82 species of nematode or parasite, more than 400 of fungal and several species of bacteria and algae [3]. The three most serious tea plant disease are camellia dieback and canker, flower light and root rot [4]. The biggest challenge for tea growers nowadays, is to produce tea without pesticide residues by growing tea in environments less favorable to pests and diseases, which may not be always possible [5]. Alternatively, it could be through choosing pesticides with low interference or by applying pesticides according to economic threshold [3], [5]. The quality of leaves, buds, fruit, flowers, and soil are vibrant to grow in which their aromas and tastes are impacted by the rainfalls percentage, concentration of secondary metabolite compounds and farmer resilience management [6].

Previous research [7] has undertaken research in diagnosing leaf diseases and tea pests by using Naïve Bayesian probabilities and Backward Chaining to produce accurate scores. Thus, this paper want to explore further the diagnose process by conducting other AI technique, which is fuzzy logic system by Mamdani Method (Min-Max Inference). Actually, this technique is quite popular among academician in which many researches had been done in various theme and disparate topics such as prediction of representative deformation modulus of tunnels, dams and mining structure [8], modeling of water movement in non-saturated soil [9], classification of toddler nutritional status [10], modelling auto zoom function in digital camera [11], delimitation of rural and urban areas on advanced cartographic visualization [12], even specific microcontroller of ARM Cortex-M4 STM32F407VG [38] and many more. The development from the scratch or adding some function to the existing software will collide with the fast development of software capabilities in software industry, which increase significantly through time to time as the result of tight competition in the market [19], [27-28]. In the context of awareness, person should have the adaptability as their preparation to fit with occurring changes or unexpected circumstances [21], [30-32]. The advantages for using fuzzy logic control (FLC) is because the understandability, flexibility, modelling of non-linear and complex function, development of expert system, collaboration with conventional control techniques and based exclusively on natural language

\section{LITERATURE REVIEW}

The paper work by Zadeh [14] on fuzzy algorithms present the new concept of formulating the control algorithm through logical rules involving a series of fuzzy conditional statement, which stated that if a set of conditions are fulfilled then a set of consequences can be inferred. In FLC terminology, a fuzzy control rule play the role of antecedent, which is a condition in the application domain and the consequent is the control action for a controlled system. The inputs of a system based on fuzzy rules must be provided by the fuzzy sets for adjustment in fuzzification of the crisp inputs and vice versa for the outputs. Normally, fuzzy logic is used to translate quantities expressed in linguistics, such as vehicle speed declared categorically, which are slow, quick, fast and turbo. It can also be used to provide the degree to which a value is true and false. Thus, this approach has advantages over the results related to human cognitive traits, especially in situations that involves the formation of concept, the recognition of pattern and decision-making in uncertain or unclear environments [20].

In general, the FLC system consists of four main parts namely fuzzification interface, fuzzy rule base, fuzzy inference engine and defuzzification interface. Mamdani and Assilian [15] introduced new technique in fuzzy inference, as the their first approach to control the combination of steam engine and boiler machines by synthesizing a set of linguistic control rules derived from experienced human operators. In addition, the linguistic variable whose values are expressed in statement, word or sentences in the form of conditions in natural language was defined by suitable membership function (MF), which is a curve that determines how each point is mapped in the input space to a membership value between 0 and 1 [22]. However, some people try to find philosophical answer on the fundamental question on why a system based on fuzzy rules work well for a wide range of practical problems. The first attempt to answer this question is quantitatively demonstrated by Wang and Buckley [16-17] where they found out that a particular FLC systems class is universal approximators, which has certain capability of approaching any real continuous 
function in a compact set with an arbitrary precision and accuracy. It is characterized by the Gaussian membership functions, fuzzy conjunction and implication product and center area of defuzzification.

The fuzzification interface involves a functions to measure the values of input variables, creating a scale mappings that transfers the range of input values variables to the corresponding universe of discourse and conduct a fuzzification function that transform it into adequate linguistic value to be displayed as a certain fuzzy set. The rule base related to the knowledge for application domain and the concurrent control objective. It consists of a database and a linguistic control rule base, which provides important definition to understand the instruction logic and data manipulation in a FLC, which characterizes the control goals and policy of the domain experts [18]. In other hand, the fuzzy inference engine is the core of a FLC, which has the ability to simulate the mechanism in human decision-making through fuzzy concepts by inferring fuzzy control actions that use fuzzy implication and the of inference rules. Since several linguistic variables are involved in the antecedents and the conclusions of a rule, the fuzzy system is called as the multi-input multioutput type [18].

Mamdani method is most often categorized as a form of approximate reasoning, which has been called as the process that allow possible imprecise conclusion is inferred from inadequate collection premise [23]. This classification and a set of IF-THEN rules can easily make someone believe that this approach can provide the logical implication of a set of rules that are used for its construction, although only approximately. In particular, Some also argued that it might be tempted to believe in this method as the shared truth of the premises ensures the truth of the conclusions [24-26]. In logics that recognized the level of partial truth, it is expected that if the inputs of the system is true up to certain point, then the outputs of the system must also correspond to the same level of certainty. Moreover, the antecedents and the consequents can also be combined propositions that include the logical connection of AND or OR. The interpretation of Mamdani method as motor for inference preservation truth is certainly challenge by the evidence and it is not shared by every academician, but still it is reasonably well-known for to the point it permeates many simulation applications [24].

\section{RESEARCH METHODOLOGY}

This research method consists of several stages namely literature study, data collection, problem analysis and problem solving. This study has objective to implement Fuzzy Mamdani method to determine the type of disease and pest in tea leaves based on several indicators or symptoms. The type of disease used in this research are limited to Tea Blister Blight (Exobasidium vexans), Leaf Spot (Cylindrocladium ilicicola), Gray Blight (Pestalotia theae), Red Root Rot (Ganoderma pseoduferreum), Black Root Rot (Rosellinia arcuata) and the type of pests namely Tea Mosquito Bug (Helopeltis spp.), Tea Tortrix (Homona coffearia) and Walker (Hyposidra talaca). There are step by step to do problem analysis in this study, which are deciding the fuzzy variable, determining the fuzzy set and domain, fuzzification to develop membership function and counting the value, creating fuzzy rule, conducting inferential system by calculating $\alpha$-predicate in each rule by MIN implication and using MAX methods for compositional for all rules, lastly defuzzification with centroid methods.

\section{DISCUSSION AND RESULTS}

In FLC, input variables used are intervals, so the input in the form of a strict number must be converted into fuzzy numbers as can be seen in the previous Table 1 that specify the weight disease and pest (WDC) and weight indicator (WI). The slight changes in the values is not necessary resulting the differences in the category but only affect the degree of membership. In this case, the category 3 is used for example in creating a set of variable and fuzzy input/output. The value is given to each disease and pest are different but a set of fuzzy to be used based on previous research as the baseline for this research for the purpose of comparison [7]. The rule for membership will be calculated in the Equation 1-4 for respective category $\mathrm{C}$ (Gray Blight) in the indicator based on weighting for indicator (C1-C4). The Figure 1 showed the used form in the application to list the data in fuzzy sets on disease and pest of tea leaves in general based on the categorization in the Table 1. After that, the fuzzy sets was created based on its specific diseases and pests, as shown in Figure 2. The Figure 3 showed the used form in the application to analyze disease and pest of tea leaves based on observation by entry the data directly through certain value in every respected indicator based on fuzzy method. 
Table 1. A Set of Tea Diasease and Pest

\begin{tabular}{|c|c|c|c|c|}
\hline No & Disease/Pest & Indicator & WDP & $\mathrm{WI}$ \\
\hline \multirow[t]{5}{*}{1} & Tea Blister Blight / & Little pale green spots & 0.8 & 0.1 \\
\hline & Exobasidium Vexans & Translucent light on young leaves & & 0.3 \\
\hline & & In $5-6$ days, the spots extends to $0.6-1.3 \mathrm{~cm}$ & & 0.5 \\
\hline & & $\begin{array}{l}\text { The surface of the spots was covered in white } \\
\text { gray dust }\end{array}$ & & 0.7 \\
\hline & & The surface of the spots protrudes downward & & 0.8 \\
\hline \multirow[t]{4}{*}{2} & Leaf Spot / Cylindrocladium & Attack on the tip of the leaf & 0.7 & 0.2 \\
\hline & ilicicola & Leaves apart from the stalk & & 0.3 \\
\hline & & The shoots dry out & & 0.5 \\
\hline & & Brown spots on the leaves & & 0.7 \\
\hline \multirow[t]{4}{*}{3} & Gray Blight / Pestalotia theae & Gray spots on the leaves with brown edges & 0.5 & 0.1 \\
\hline & & Mushrooms spread to shoots & & 0.4 \\
\hline & & The shoots dry out & & 0.6 \\
\hline & & Twigs broken and yellowing & & 0.8 \\
\hline \multirow[t]{6}{*}{4} & Red Root Rot / Ganoderma & The leaves turn yellow & 0.6 & 0.2 \\
\hline & pseoduferreum & The leaves wither & & 0.3 \\
\hline & & The leaves fall out & & 0.4 \\
\hline & & Plants die & & 0.6 \\
\hline & & There are red threads in root surface & & 0.7 \\
\hline & & $\begin{array}{l}\text { Wood on the sick root is soft and draws water } \\
\text { when pressed }\end{array}$ & & 0.9 \\
\hline \multirow[t]{6}{*}{5} & Black Root Rot / Rosellinia & The leaves turn yellow & 0.2 & 0.2 \\
\hline & arcuata & The leaves wither & & 0.4 \\
\hline & & The leaves fall out & & 0.5 \\
\hline & & Plants die & & 0.6 \\
\hline & & There are black fungi threads in root surface & & 0.7 \\
\hline & & There are black dots on wood of the roots & & 0.8 \\
\hline \multirow[t]{4}{*}{6} & Tea Mosquito Bug / Helopeltis & Attack occur on leaves or shoots & 0.7 & 0.2 \\
\hline & spp & Black spot on tea leaves & & 0.4 \\
\hline & & Branches or buds have concave spots & & 0.6 \\
\hline & & Twigs withered and dry & & 0.8 \\
\hline \multirow[t]{5}{*}{7} & Tea Tortrix / Homona coffearia & There are bite marks on the leaves & 0.5 & 0.2 \\
\hline & & Larvae eat tea leaves & & 0.4 \\
\hline & & Attacking young leaves & & 0.5 \\
\hline & & Leaves perforated & & 0.6 \\
\hline & & Leaf buds bald & & 0.8 \\
\hline \multirow[t]{3}{*}{8} & Walker / Hyposidra talaca & The buds are rolled up & 0.3 & 0.3 \\
\hline & & There are fine threads on the shoots & & 0.5 \\
\hline & & There are damages on the part of that is rolled up & & 0.8 \\
\hline
\end{tabular}

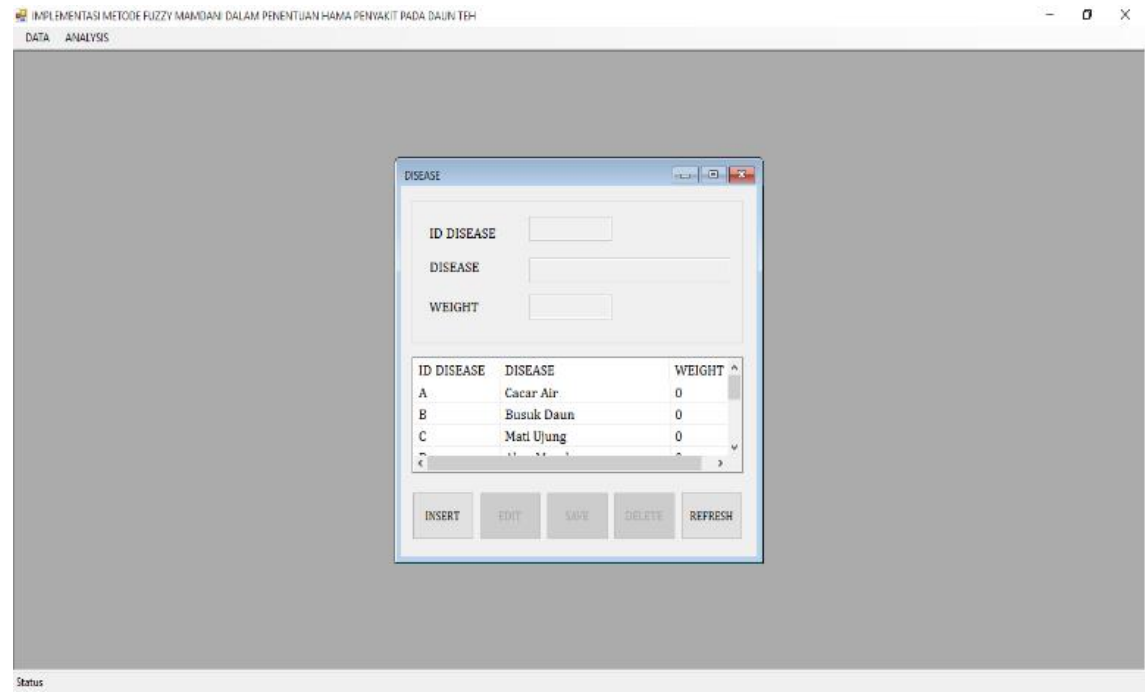

Figure 1. Application Form Interface 


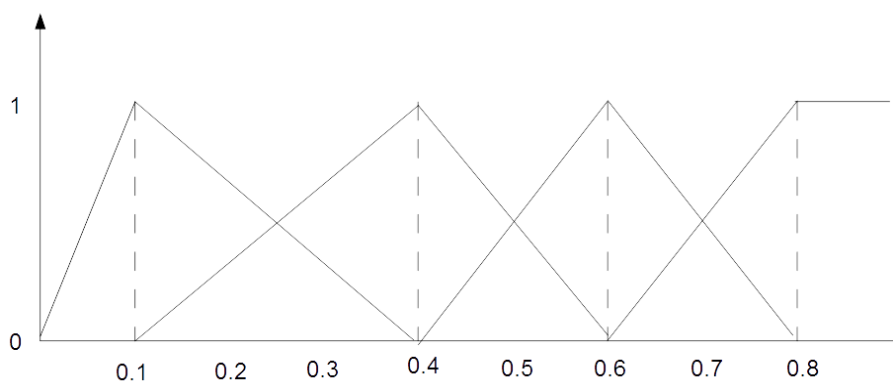

Figure 2. A Set of Fuzzy Gray Blight

$$
\begin{aligned}
& \mu \mathrm{A} 1[\mathrm{x}]=\left\{\begin{array}{c}
0, x \leq 0 \text { atau } x \geq 0.4 \\
\frac{x-0}{0.1-0}, 0 \leq x \leq 0.1 \\
\frac{0.4-x}{0.4-0.1}, 0.1 \leq x \leq 0.4
\end{array}\right. \\
& \mu \mathrm{A} 2[\mathrm{x}]=\left\{\begin{array}{c}
0, x \leq 0.1 \text { atau } x \geq 0.6 \\
\frac{x-0.1}{0.4-0.1}, 0.1 \leq x \leq 0.4 \\
\frac{0.6-x}{0.6-0.4}, 0.4 \leq x \leq 0.6
\end{array}\right. \\
& \mu \mathrm{A} 3[\mathrm{x}]=\left\{\begin{array}{c}
0, x \leq 0.4 \text { atau } x \geq 0.8 \\
\frac{x-0.4}{0.6-0.4}, 0.4 \leq x \leq 0.6 \\
\frac{0.8-x}{0.8-0.4}, 0.6 \leq x \leq 0.8
\end{array}\right. \\
& \mu \mathrm{A} 4[\mathrm{x}]=\left\{\begin{array}{c}
0, x \leq 0.6 \\
\frac{x-0.6}{0.8-0.6}, 0.6 \leq x \leq 0.8 \\
1, x \leq 0.8
\end{array}\right.
\end{aligned}
$$

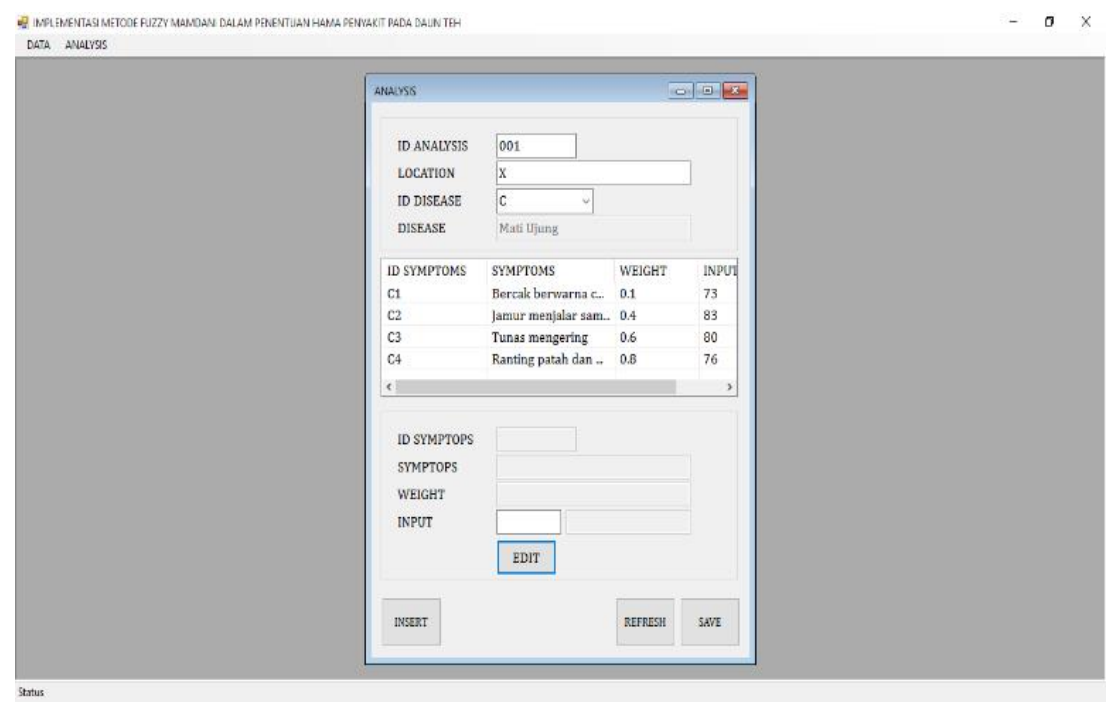

Figure 3. Problem Analysis for Gray Blight Disease 


\begin{tabular}{|c|c|c|c|}
\hline Set of Data & Input Code & Output Code & Domain \\
\hline Less (L) & $\mathrm{X} 1$ & $\mathrm{Y} 1$ & $0-45$ \\
\hline Enough (E) & $\mathrm{X} 2$ & Y2 & $40-75$ \\
\hline Good $(\mathrm{G})$ & X3 & Y3 & $70-100$ \\
\hline
\end{tabular}

In membership function, it has interval 0 to 1 and for curve $\mathrm{x}$, value of each variable from 0 to 100 . Therefore, to determine the point of its membership using the trapezoid curve repression because it can be measured accordingly and precisely in regard to the limits of each domain. On each side, it uses a curve to terminate the variable of a fuzzy zone. In addition, the membership functions for each set are:

a. A Set of Less (L)

$$
\mu \mathrm{A} 1[\mathrm{xi}]=\left\{\begin{array}{c}
0, x \leq a \\
\frac{b-x i}{b-a}, a \leq x i \leq b
\end{array}\right.
$$

b. A Set of Enough (E)

$$
\mu \mathrm{A} 2[\mathrm{x}]=\left\{\begin{array}{r}
(x i-a) /(b-a), a \leq x i \leq b \\
1, b \leq x i \leq c \\
(d-x i) /(d-c), c \leq x i \leq d
\end{array}\right.
$$

c. A Set of Good (G)

$$
\mu \mathrm{A} 3[\mathrm{x}]=\left\{\begin{array}{c}
(x i-c) /(d-c), c \leq x i \leq d \\
1, x i \geq d
\end{array}\right.
$$

Where: $a=$ Minimum value of less

$\mathrm{b}=$ Maximal value of less

$\mathrm{c}=$ Minimum value of enough

$\mathrm{d}=$ Maximal value of enough

Once the variables and set are formed, the application of the implication function is performed. For example there is a case on Gray Blight as follows, the extent to which the tea leaves are insulated by the disease and pest of Pestalotia theae if the value is matched. A crucial consequence of the MAX aggregation method is that IF-THEN rules in a Mamdani system have effects on the final output of the system that cannot be analyzed independently of other IF-THEN rules that may be fired simultaneously in the system [24], [26], [35-37].

Table 3. A Set of Tea Disease and Pest

\begin{tabular}{lllc}
\hline No & Code & Indicator & Value \\
\hline 3. & C1 & Gray spots on the leaves with brown edges & 73 \\
& C2 & Mushrooms spread to shoots & 83 \\
& C3 & The shoots dry out & 80 \\
& C4 & Twigs broken and yellowing & 76 \\
\hline
\end{tabular}

The rule derived from the data value of end-diseased disease is

1. If $\mathrm{C} 1$ is enough, $\mathrm{C} 2$ is good, $\mathrm{C} 3$ is good, and $\mathrm{c}$ is good, then predicate value (PV) is attacked

2. If $\mathrm{C} 1$ is good, $\mathrm{C} 2$ is good, $\mathrm{C} 3$ is good, and $\mathrm{C} 4$ is good, then PV is attacked

After getting the rule then look for membership value and implication value:

A. If C1 is Enough C2 Good, C3 Good, and C4 Good, Then PV Against. After the membership value is obtained, then look for the implication value (MIN). and the MIN value of this rule:

$\alpha \_$predicate $1=\mu \mathrm{C} \cap \mu \mathrm{B} \cap \mu \mathrm{B} \cap \mu \mathrm{B}=\min (0.4 .1,1,1)=0.4$

B. If C1 Good C2 Good, Good C3, and C4 Good, Then PV Against. After the membership value is obtained, then look for the implication value (MIN). and the MIN value of this rule:

$\alpha \_$predicate $1=\mu \mathrm{C} \cap \mu \mathrm{B} \cap \mu \mathrm{B} \cap \mu \mathrm{B}=\min (0.6 .1,1,1)=0.6$ 
After the implication value is obtained, the next step is the composition of the rule that takes the MAX value of the implication value that exists:

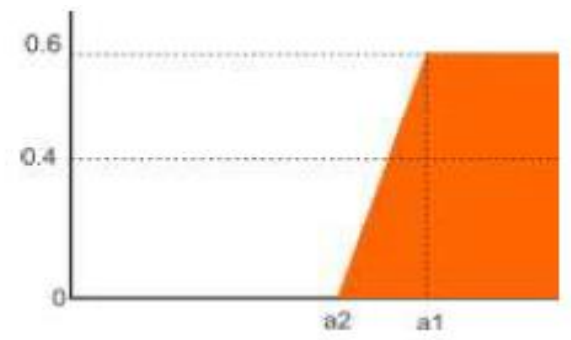

Figure 4. Graphic Result for Composition Rules

$(\mathrm{a} 1-70) /(75-70)=0.6=>\mathrm{a} 1=73$

$(\mathrm{a} 2-70) /(75-70)=0 \Rightarrow \mathrm{a} 2=70$

Having obtained the value of a1 and a 2 then the membership function can be formed based on the decomposition result as follows:

$$
\mu[\mathrm{x}]=\left\{\begin{array}{c}
0, x \leq 70 \\
(70-x) /(75-70), 70 \leq x \leq 73 \\
0.6, x \geq 73
\end{array}\right.
$$

The analysis result can help decision making in determining the current status of tea leaves for further action. The last process is using centroid method for defuzzyfication, which indicated $86 \%$ of category C (Gray Blight) with the following result:

$\mathrm{X}^{*}=\frac{M 1+M 2+M 3}{A 1+A 2+A 3}$

$\mathrm{X}^{*}=\frac{\int_{0}^{70} 0 z d z \int_{70}^{73} \frac{(70-x)}{(75-70)} z d z \int_{73}^{100} 0.6=z d z}{(73 * 0)+((0+0.6) *(73-70))+((100-73) * 0.6)}$

$X^{*}=\frac{0+(-64,8)+(1530)}{0+(0.9)+(16.2)}$

$X^{*}=\frac{1465.2}{17.1}$

$\mathrm{X}^{*}=86.212$

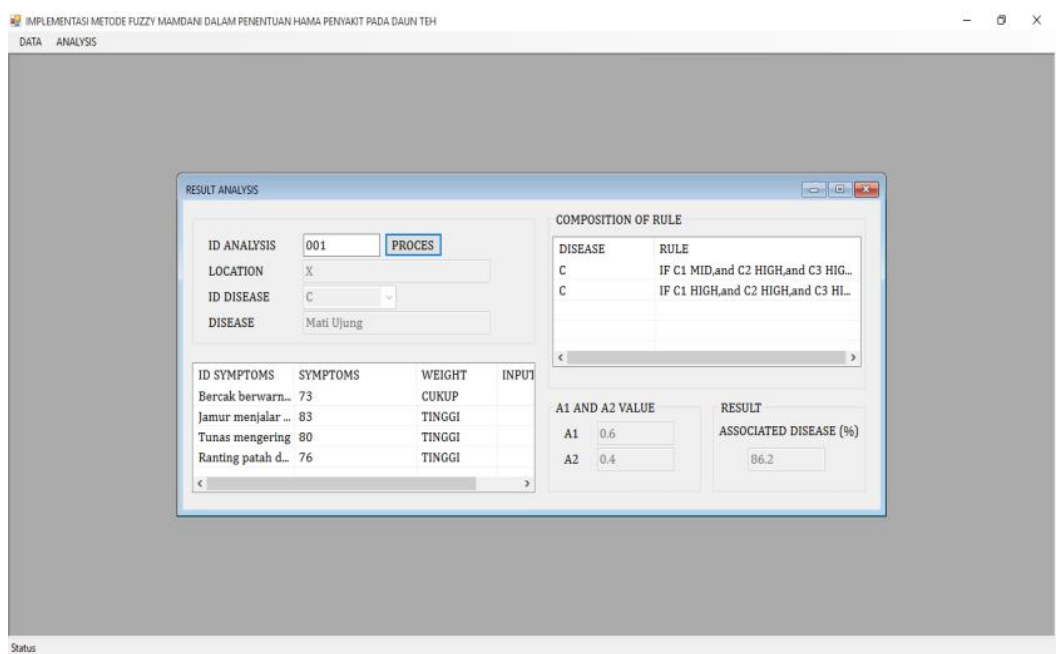

Figure 5. Problem Result for Composition Rules by Application 
The Figure 5 showed the final result in the analysis process for tea leaves based on Fuzzy Mamdani Inference, which is implemented in the application to help farmers diagnose the type of disease and pest, which attacked the tea leaves. In large scale, after the trial and error test, it is expected the application can be used for decision making process to further reduce the burden in gardening management. On the other hand, the efficiency also become the primary objective to select specific application to be used. The comparison with previous method also has been calculated that showed $78 \%$, lower efficiency compare to fuzzy methods as follows:

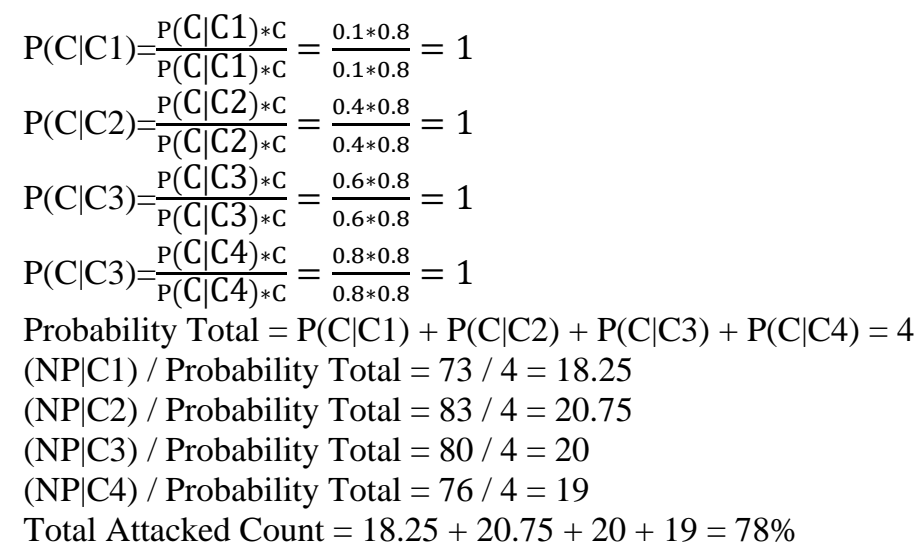

\section{CONCLUSION}

In summary, this study uses the Mamdani fuzzy inference method within the 6 (six) phases namely the determination of the fuzzy variables, fuzzy sets and fuzzy domains, adjustment for fuzzification, the formation of fuzzy rule in the form of IF-THEN, inference using Mamdani method that is min implication function (minimum) and max rule composition (maximum) and lastly, defuzzification. In addition, working with different implications and at the same time, the possibility of combining the result given by the implications of these, therefore, offer a solid basis for a more accurate results of computational application system to be developed. Moreover, it can be improved by adding new implications, by using more fuzzy matching techniques or by other aggregate operators to obtain an overall crisp action from those provided, separately through every implication. One of the concern of our future study is to expand this system by include uncertainty about the series of fuzzy membership function associated with the linguistic terms. It also want to compare the efficiency of this method with others in similar object or target to grasp more understandable of its strengths and weaknesses.

\section{REFERENCES}

[1] Hicks A. "Review of Global Tea Production and the Impact on Industry of the Asian Economic Situation". Retrieved from http://citeseerx.ist.psu.edu/viewdoc/download?doi=10.1.1.543.8931\&rep=rep1\&type=pdf

[2] Kaison C. "World Tea Production and Trade Current and Future Development". Food and Agriculture Organization of the United Nations. Trade and Markets Division, Rome 2015.

[3] Ahmed M. "Ecofriendly pest management of tea in Bangladesh". Two and a Bud 59 (2012), 11-16.

[4] Clemson. "Camellia Diseases \& Insect Pests". Home \& Garden Information Center (HGIC), 2013.

[5] Danzinger HL. "Diseases and Pests of Tea: Overview and Possibilities of Integrated Pest and Disease Management". Journal of Agriculture in the Tropics and Subtropics 101 (April 2000) 13-38.

[6] Ahmed S. "Tea and the Taste of Climate Change: Understanding Impacts of Environmental Variation on Botanical Quality". Herbalgram 103 (2014), 44-51.

[7] Tarigan MP. "Implementasi Metode Naïve Bayesian dan Backward Chaining pada Sistem Pakar Diagnosa Penyakit/Hama Tanaman Teh". Bachelor Essay (2016). Universitas Sumatera Utara.

[8] Rezaei M, Asadizadeh M, Majdi A, Hossaini MF. "Prediction of representative deformation modulus of longwall panel roof rock strata using Mamdani fuzzy system”. International Journal of Mining Science and Technology 25 (2015) 23-30.

[9] Afonso ACM, Netto AM, de Vasconcelos E. "Fuzzy Logic Applied to the Modeling of Water Dynamics in an Oxisol in Northeastern Brazil”. Revista Brasileira de Ciencia do Solo 38(2) Apr 2004.

[10] Permatasari D, Azizah IN, Hadiat HL, Abadi AM. "Classification of Toddler Nutritional Status using Fuzzy Inference System (FIS)”. AIP Conference Proceedings 1868, 040007 (2017).

[11] Elamvazuthi I, Vasant P, Webb J. "The Application of Mamdani Fuzzy Model for Auto Zoom Function of a Digital Camera". IJCSIS 6(3) 2009. 
[12] Paszto V, Brychtova A, Tucek P, Marek L, Burian J. "Using a Fuzzy Inference System to Delimit Rural and Urban Municipalities in the Czech Republic in 2010". Journal of Maps 11(2) 2015.

[13] Ahlan AR, Lubis M, Lubis AR. "Information Security Awareness at the Knowledge-Based Institution: Its Antecedents and Measures". Procedia Computer Science 72 (2015), 361-373.

[14] Zadeh LA. "Calculus of fuzzy restrictions". in L. A. Zadeh, K.-S. Fu, K. Tanaka \& M. Shimura (eds), Fuzzy Sets and their Applications to Cognitive and Decision Processes, Academic Press, 1975, New York, pp. 1-39.

[15] Mamdani EH. "Application of fuzzy logic to approximate reasoning using linguistic synthesis". IEEE Transactions on Computers 1977, 26(12): 1182-1191.

[16] Wang, LX. (1992). "Fuzzy Systems are Universal Approximators", Proc. of IEEE Inter. Conf. on Fuzzy Systems, San Diego, USA, pp. 1163-1170.

[17] Buckley JJ. (1993). "Sugeno type controllers are universal controllers", Fuzzy Sets and Systems Vol. 53: $299-304$.

[18] Iancu I. "A Mamdani Type Fuzzy Logic Controller". Fuzzy Logic - Controls, Concepts, Theories and Application". Prof. Elmer Dadios (ed.). ISNB: 978-953-51-0396-7. InTech 2012.

[19] Ibtisam bt. Yaacob N. and Lubis M. "Multi Agent Integration Model for Agen Executive Information System: A Case Studv in KUIS". IIUM Press. Kuala Lumpur. ISBN 9789674180843 in Kartiwi, Mira and M.Z.M Khedher, Akram, eds. (2011) Data management: issues, challenges and opportunities.

[20] Abrori M, Prihamayu AH. "Aplikasi Logika Fuzzy Metode Mamdani dalam Pengambilan Keputusan Penentuan Jumlah Produksi”. Kaunia Vol. XI (2) October 2015/1436: 91-99.

[21] Ahlan AR, Lubis M. "Information Security Awareness in University: Maintaining Learnability, Performance and Adaptability through Roles of Responsibility". Int. Conf. of IAS 2011.

[22] Mahalakshmi P, Ganesan K. "Mamdani Fuzzy Rule based Model to Classify Sites for Aquaculture Development". Indian J. Fish 62(1): 110-115, 2015.

[23] Pal SK, Mandal DP. "Fuzzy Logic and Approximate Reasoning: An Overview". IETE J. Res. 37 (2015) 548-560.

[24] Izquierdo SS, Izquierdo LR. "Mamdani Fuzzy Systems for Modeling and Simulation: A Critical Assessment". SSRN Electronic Journal (2017), DOI: 10.2139/ssrn.2900827

[25] Klawonna F, Novák V. "The Relation between Inference and Interpolation in the Framework of Fuzzy Systems". Fuzzy Sets Syst. 81 (1996) 331-354.

[26] Klir GJ, Yuan B. "Fuzzy Sets and Fuzzy Logic: Theory and Applications". Prentice Hall PTR, Upper Saddle River, New Jersey, 1995.

[27] Ibtisam bt. Yaacob N. and Lubis M. "Data Accuracy and Agent Integration in Executive Information Svstem: A Case Study in KUIS". IIUM Press. Kuala Lumpur. ISBN 9789674180843 in Kartiwi, Mira and M.Z.M Khedher, Akram, eds. (2011) Data management: issues, challenges and opportunities.

[28] Lubis AR, Fachrizal F, Lubis M. "The Effect of Social Media to Cultural Homecoming Tradition of Computer Students in Medan". Procedia Computer Science, 124, pp. 423-428, 2017.

[29] Lubis AR. "Implementation of Divide and Conquer Technique: Karatsuba Algorithm for Multipliccation Big Integer with Phyton". Jurnal Saintek vol. 28 (2), 2014.

[30] Oliveira DN, de Lima Heen GA, Almeida OM. "Design and Implementation of a Mamdani Fuzzy Inference System on an FPGA using VHDL". Annual Conference of the North American Fuzzy Information Processing Society NAFIPS, July 2010.

[31] Tarigan P, Sinurat S, Sinambela M. "Implementation of a Mamdani fuzzy logic controller for building automation using electronic control based on AT89S51". IEEE TIME-E 2015.

[32] Hasan MH, Abdul Aziz I, Jaafar J, Abdul Rahim L, Manyiel JMA. "A comparative study of Mamdani and Sugeno fuzzy models for quality of web services monitoring". IJACSA vol. 8(9), 2017.

[33] Hakim L, Kusumasari TF, Lubis M. "Text mining of UU-ITE Implementation in Indonesia". Journal of Physics: Conference Series 1007 (1), 2018.

[34] Lubis AR, Fachrizal F, Lubis M, Tahir HM. "Wireless service at public university: A survey of users perception on security aspects". IEEE ICOIACT 2018.

[35] Tan L. "Takagi-Sugeno and Mamdani Fuzzy Control of a Resort Management System". Master Thesis, November 2011. Blekinge Institute of Technology.

[36] Kamboj V, Kaur A. "Comparison of constant Sugeno-type and Mamdani-type fuzzy inference system for lead sensor". IJSCE, vol. 3 (2), May 2013.

[37] Wang C. "A study of membership functions on Mamdani-type fuzzy inference system for industrial decisionmaking". Theses and Dissertations, Paper 1665, 2015.

[38] Wyrwol B, Hrynkiewicz E. "Implementation of the FITA fuzzy inferencce system on the specific microcontroller platform". IFAC-PapersOnLine vol. 48(4), pp. 165-169, 2015. 